\title{
Burn Patients at Western Regional Hospital of Nepal: An Epidemiological Study
}

\section{Amar Gurung ${ }^{1}$, Dilip Baral ${ }^{1}$, Narendra Vikram Gurung${ }^{1}$, Arjun Acharya ${ }^{1}$, Suresh Raj Poudel ${ }^{1}$, Santosh Shrestha ${ }^{1}$, Devendra Shrestha ${ }^{1}$}

${ }^{1}$ Department of General Surgery, Pokhara academy of health Sciences, Gandaki, Pokhara

\section{Correspondance:}

Dr. Dilip Baral, MS

Department of General Surgery

Pokhara Academy of Health Sciences

email: baraldilip@yahoo.com

Article received: Oct 142019

Article accepted: Jan 302020

\section{ABSTRACT}

Background: Burn injury is one of the major causes of morbidity and mortality in our country. Study of epidemiological characteristics of burn injury helps in planning of the prevention and upgradation of its treatment facility.

Material and Methods: This is a hospital based retrospective epidemiological study of the burn patients admitted in our center from September 2018 to April 2019.

Results: In total 52 patients were included in this study. There was a slight preponderance of female patients over male patients. Mean age of the patients was $34.77 \pm 29.16$ years. Eighty percentage of burn injury occurred inside house. Majority of burn cases were scald burn followed by flame burn. Percentage total body surface area involved in burn had a mean of $14.183 \pm 8.224$. Lower extremity was the most commonly involved area. Total duration of hospital stay was $18.21 \pm 13.656$ days. Out of total patients only four patients needed admission in Intensive Care Unit (ICU). Regarding outcome, $88.5 \%$ patients survived while $9.6 \%$ patients died and $1.9 \%$ patient went on discharge on request.

Conclusion: Burn injury is a preventable condition with high rate of morbidity and mortality. Burn patients have prolonged hospital stay as recovery is slow. Awareness programs for prevention of burn injury are needed to decrease the incidence of the burn injury.

Keywords: Burn, Epidemiology, Nepal, Western region.
INTRODUCTION

Burn injury is one of the leading cause of morbidity and mortality in the world. World Health Organization ( WHO) estimates that 1,80,000 burn related deaths occurs every year, out of which the vast majority occurs in low to middle-income countries (African and southeast Asian countries).

According to WHO burn is the second leading cause of injury in rural Nepal accounting for $5 \%$ of disabilities. $^{2}$

Burn injury along with the morbidity and mortality associated with it has psychological, economic 
Original Article

and social impact on the patient and their family members. With adequate awareness program it is a preventable condition. To conduct a well-designed awareness programme, the knowledge about the pattern of burn injuries, their associated risk factors is quite essential. Nonetheless, adequate and systematic management of burn injuries can reduce the morbidity and mortality related to it. In a country like ours, there is a wide difference between the available resources and the number of burn cases. Our country has very few functional specialized burn units and manpower. So, burn patients who require specialized care are also managed in a low resource setup by the general surgeons who do not have specialized training of managing a severe burn case.

To the best of our knowledge, till the date of conduction of the study, our center is the only center in the Gandaki Province of our country which has a ward designated to burn patients. Our center has five beds in surgery ward which are allocated to the burn patients and the cases are managed by the general surgeons. The present study was done to figure out the demography of the burn injuries admitted in the burn ward of the surgery department of our hospital. Results from this study can guide to promulgate preventive measures in burn injuries. Moreover, it will also help in developing and monitoring changes in the available care and outcome of burn injuries of the region.

\section{MATERIALS AND METHODS}

A retrospective descriptive study was conducted at the burn unit of the department of surgery of Pokhara Academy of Health Sciences from September 2018 to April 2019. All the patients, admitted to the burn unit of the department were included in the study. Burn patients receiving treatment from outpatient department and patients brought dead to hospital were excluded from the study. Data regarding patients age, sex, comorbidities, place of burn, mode of burn injury, time of presentation after burn injury, site and percentage burn injury, intervention done, duration of hospital stay and outcome of management were collected from the patient record section of our hospital and filled in a preformed performa which was later entered in Microsoft
Medical Journal of Pokhara Academy of Health Sciences Vol. 3 Issue 1 excel spreadsheet and analyzed. Ethical permission was obtained from the hospital administration.

\section{RESULTS}

In total, 52 patients were included in this study. Out of which $28(53.8 \%)$ were female whereas 24 (46.2\%) were male. Mean age of the patients was $34.77 \pm 29.16$ years which ranged from 1 year to 85 years.

Regarding place of burn, $42(80 \%)$ burn injury occurred inside house while $10(20 \%)$ occurred outside house. Mean time of presentation to the hospital after the incident was $6 \pm 3.30$ hours.

Before presentation to the hospital 8 (15.38\%) patients had received first aid at other center while $44(84.61 \%)$ patient hadn't received any first aid.

Mode of burn injury is as shown in table 1. Majority of burn cases were scald burn (48.1\%) followed by flame burn (44.2\%), electrical and others (chemical).

\section{Table 1: Mode of burn injury}

\begin{tabular}{llc}
\hline \multicolumn{1}{c}{$\begin{array}{c}\text { Mode of Burn } \\
\text { injury }\end{array}$} & \multicolumn{1}{c}{$\begin{array}{c}\text { No. of patients } \\
(\mathbf{N})\end{array}$} & \% \\
\hline Scald & 25 & $48.1 \%$ \\
\hline Flame & 23 & $44.2 \%$ \\
Electrical & 3 & $5.8 \%$ \\
\hline Others & 1 & $1.9 \%$ \\
\hline
\end{tabular}

Percentage total body surface area involved in burn had a mean of $14.18 \pm 8.22$. Minimum percentage total body surface area involved was $2 \%$ whereas maximum was $50 \%$. Most of our patients had second degree superficial burn. Lower extremity was the most commonly involved area of the body followed by upper extremity. Areas of the body involved in burn are as shown in table 2 . 
Table 2: Different Body parts involved in Burn Injury

\begin{tabular}{lll}
\hline \multicolumn{1}{c}{$\begin{array}{c}\text { Involved Body } \\
\text { Parts }\end{array}$} & $\begin{array}{c}\text { No. of } \\
\text { patients(N) }\end{array}$ & \multicolumn{1}{c}{$(\%)$} \\
\hline Head and Neck & 10 & $19.2 \%$ \\
Upper extremities & 18 & $34.6 \%$ \\
Lower extremities & 24 & $46.1 \%$ \\
Chest & 12 & $23 \%$ \\
Abdomen & 14 & $26.9 \%$ \\
Back & 8 & $15.3 \%$ \\
Perineum & 2 & $3.8 \%$ \\
\hline
\end{tabular}

Forty four $(84.6 \%)$ patients were managed with routine plus collagen dressing only whereas five $(9.61 \%)$ patients required debridement and three $(5.76 \%)$ patients underwent debridement plus split skin graft.

Total duration of hospital admission had a mean of $18.21 \pm 13.65$ days with a range of minimum 2 days to maximum 60 days. Four $(7.69 \%)$ patients were admitted in ICU. The reason for ICU admission was involvement of airway by burn in two patients and shock in two patients. Forty-eight $(92.30 \%)$ patients were admitted in the burn unit of the hospital.

Regarding outcome 46 (88.5\%) patients survived while five $(9.6 \%)$ patients died and one $(1.9 \%)$ patient went on discharge on request. Those patients who died had total body surface area involved in burn more than 25 percentage. The cause of death in those patients were sepsis leading to multi organ failure.

\section{DISCUSSION}

This study highlights the data of the burn patients admitted to the burn unit of the surgery ward of the western regional hospital. In a developing country like Nepal, burn injuries, morbidity and mortality related to it represents a serious health problem.

In the present study, burn injury was slightly more common in females than in males which is quite similar to other studies. ${ }^{3-6}$ This might be because females are mostly involved in the household activities and household activities like cooking are the main culprit of burn injury in our scenario. The mean age of the people who had suffered burn injury in our study was also quite similar to the other studies. ${ }^{6,7}$ This study revealed that the majority of burn injuries occurred inside the house, which goes along with the systemic review done by Tripathee et al. ${ }^{8}$

Scald burn injury was the commonest mode of injury followed by flame burn injury in this study, which is a bit different that other previous studies that showed flame burn as the commonest mode of injury ${ }^{3,5}$. This difference might be due to different socio-environment condition of the samples and small size of the study population.

First aid prior to hospital admission was received by very few number of the patients, this is possibly due to lack of knowledge, illiteracy, unavailability of the facility.

Mean total body surface area involved in burn injury in our study was $14.18 \%$, which was more or less similar to other studies. ${ }^{3,7}$ Lower extremities were the most common site involve in burn injuries followed by upper extremities which is also similar to the available studies. ${ }^{5}$

Only a few number of patients included in this study needed intervention like debridement and split skin graft whereas majority were treated with routine and collagen only. This might be because most of our patients had second degree superficial burns. This study shows that meticulous dressing is vital in the management of patients with second degree superficial burn.

This study has limitation in terms of short duration of study and study size. There are limited studies regarding burn from our region, so, this study surely embarks for further study in burn from our region. Moreover, we believe that this study will help the regional policy makers for enriching the burn management and formulating preventive measures.

\section{CONCLUSION}

After burn injury, recovery is slow and often burn patients have prolong hospital stay. Females 
are more commonly affected with burn injury. Awareness programs should be conducted to decrease the occurrence of the burn injury. There is a need of establishment of more sophisticated burn care unit in our region.

\section{REFERENCES}

1. Burns. https://www.who.int/news-room/factsheets/detail/burns. Accessed August 24, 2019.

2. Burns. https://www.who.int/news-room/factsheets/detail/burns. Accessed August 21, 2019.

3. Tripathee S, Basnet SJ. Epidemiology and outcome of hospitalized burns patients in tertiary care center in Nepal: Two year retrospective study. Burn Open. 2017;1(1):1619. doi:10.1016/j.burnso.2017.03.001

4. Krishnamurthy V. R., Ishwaraprasad G. D., Sumana M. SUC. Pattern of burn injury admissions at a teaching hospital of Karnataka, India: a three year retrospective study. Int Surg J. 2018;5(12):3930. doi:10.18203/2349-2902.isj20185021

5. Karki B, Rai SM, Nakarmi KK, et al. Clinical Epidemiology of Acute Burn Injuries at Nepal Cleft and Burn Centre, Kathmandu, Nepal. Ann Plast Surg. 2018;80(3):S95-S97. doi:10.1097/SAP.0000000000001270

6. Panda S, Mohapatra M, Jena UK, et al. An epidemiological study of burn cases admitted to a tertiary care centre of Odisha. Int $\mathrm{J}$ Community Med Public Heal. 2018;5(2):616. doi:10.18203/2394-6040.ijcmph20180238

7. Rai SM, Karki B, Nakarmi $K$, et al. Retrospective study on early outcome of acute burn injuries treated at Nepal Cleft and Burn Centre of Public Health Concern Trust-Nepal. J Nepal Health Res Counc. 2014;12(28):195-199.

8. Tripathee S, Basnet SJ. Erratum to: Epidemiology of burn injuries in Nepal: a systemic review. Burn Trauma. 2017;5(1):16. doi:10.1186/s41038-017-0081-0 